\title{
"PASS THE FLAME": TENTATIVE PROGRAMS OF CULTURAL HERITAGE EDUCATION AMONG TEENAGERS IN YUANMINGYUAN SITE
}

\author{
R. Ni ${ }^{\text {a }}$ L. Yin ${ }^{\text {a }}$, T. Liu ${ }^{\text {a }}$, X. Zhang ${ }^{\text {a }}$ \\ ${ }^{a}$ Tsinghua Heritage Institute for Digitization, Beijing, China - (niruifeng, yinlina, liuting, zhangxianru)@thid.cn
}

KEY WORDS: Culture Heritage, Teenagers, Education, School Curriculums, Summer Camp, International Symposium

\begin{abstract}
:
Yuanmingyuan is a very important cultural heritage site in Beijing, China. In order to improve the conservation of Yuanmingyuan Site and increase communication between the cultural heritage site and the public, especially the teenagers, our institute initiated a serial of education programs in the past two years, cooperating with local schools, including courses on the base of school curriculums, independent cultural heritage summer camp, and special sessions in international cultural heritage symposium. All these programs have received positive feedback and shown promising future.
\end{abstract}

\section{INTRODUCTION}

Yuanmingyuan (圆明园), also known as The Old Summer Palace, located in the northwestern suburb of Beijing, was originally constructed in 1707 , during the reign of the Kangxi (康熙) Emperor of Qing Dynasty, to be granted to the Emperor's fourth son, Prince Yong named Yinzhen (雍亲王胤 禛). After he succeeded to the throne as Yongzheng (雍正) Emperor in 1722, Yinzhen expanded Yuanmingyuan from a prince's residence and garden to a magnificent complex of imperial palaces and gardens. From then on, five generations of emperors - Yongzheng, Qianlong (乾隆), Jiaqing (嘉庆), Daoguang (道光) and Xianfeng (咸丰) - kept expanding and constructing Yuanmingyuan, to an area of 3.5 square kilometres, with hundreds of structures such as halls, pavilions, temples, galleries, gardens, lakes, and bridges. It was known to the world as the "Garden of Gardens" at its time. In 1860, during the Second Opium War, Yuanmingyuan was looted and burnt to ruins by the invading Anglo-French Forces. In 1980s, the Yuanmingyuan site was cleared up by Chinese government and opened to public.

Yuanmingyuan site has been one of the National Patriotic Education Bases since 1994, and the nearby schools have been choosing Yuanmingyuan for students' field trips and coming-toage ceremonies. However, the value of Yuanmingyuan as a cultural heritage site in education has not been fully acknowledged and explored.

The ICOMOS Guidelines for Education and Training in the Conservation of Monuments, Ensembles and Sites (Colombo, 1993) pointed out that "there is a need to impart knowledge of conservation attitudes and approaches to all those who may have a direct or indirect impact on cultural property," and "education and sensitization for conservation should begin in schools and continue in universities and beyond. These institutions have an important role in raising visual and cultural awareness... and giving the cultural preparation".

Later, The ICOMOS Charter for the Interpretation and Presentation of Cultural Heritage Sites (Quebec, 2008) stated in its preamble that "ICOMOS charters stress the importance of public communication as an essential part of the larger conservation process" and that "every act of heritage conservation...is by its nature a communicative act." The
Charter aimed, as the first of its 7 major objects, to "facilitate understanding and appreciation of cultural heritage sites and foster public awareness and engagement in the need for their protection and conservation." Under the principle of "Research, Training, and Evaluation", it pointed out that "every interpretation program should be considered as an educational resource for people of all ages. Its design should take into account its possible uses in school curricula, informal and lifelong learning programs, communications and information media, special activities, events, and seasonal volunteer involvement."

Based on these understandings, objects and principles, our Institute, as one key organization in research, planning and conservation of Yuanmingyuan site, initiated a serial of education programs in the past two years, cooperating with local schools, especially the Tsinghua High School (THHS).

\section{PROGRAM DESIGN}

We mainly consulted the kit book of the UNESCO World Heritage Education Program: World Heritage in Young Hands. According to the kit book, "the outstanding values and the universal importance of conserving World Heritage...offer many unique, and often multidisciplinary and interdisciplinary teaching and learning opportunities", and given that "the curriculum is already overloaded in most schools and more demands are constantly being made on teachers", the book recommended an integrated, multi-disciplinary approach, which allows teachers in different disciplines, such as history, geography, science or language, to introduce elements of World Heritage education into classroom teaching. It suggested that teachers of different disciplines work together in teams that will impart to students the desire to know, to cherish and to act in favor of World Heritage conservation. That was exactly how we carried out our educational programs, together with the dedicated, multidisciplinary teachers of THHS. Here we will present three cases of the programs. 


\section{CASE STUDIES}

3.1 Case 1: "Into Yuanmingyuan" and "Traditional Chinese Architectures and Gardens"-cultural heritage courses on the base of school curriculums

Since the first half year of 2013, our institute, taking use of the achievements and resources accumulated in its long-term research about Yuanmingyuan, has initiated a series of education programs by cooperating with THHS. The programs include two culture-and-science-oriented courses, i.e. the course "Into Yuanmingyuan" for junior students and the "Traditional Chinese Architectures and Gardens" for seniors.

"Into Yuanmingyuan" for juniors is a course developed by our institute and THHS in accordance with the National Outline for Medium and Long-term Education Reform and Development (2010-2020). Following and directed by the education goal set up in the outline - to promote students' overall development, to focus on improve students' ..... and help them develop innovative spirit to explore and practical problem-solving skills", and the main spirit of the outline, i.e. "pay attention to the combination of both studying and thinking; advocate the heuristic method, inquiry method, discussion approach and participatory approach in teaching, and help students learn how to study", our institute, taking advantage of THHS's unique advantage in location (just near Yuanmingyuan), designed this course for the first grade of junior students.

The course is closely integrated with the high school's compulsory curriculums, such as language, mathematics, English, history, politics, geology and art; teachers of all the mentioned disciplines all participate in the "Into Yuanmingyuan" course teaching. The course lasts for about a year, and can be divided into two stages: the first one is "learning about" and "experiencing" Yuanmingyuan, and the second one "Studying" and "presenting" Yuanmingyuan.

The first stage is mainly knowledge instruction and preparation provided by a multi-disciplinary team with various professions and expertise. In this stage, professionals from our institute and fellow teachers from THHS work together to design and conduct a series of wide-range and rich-content lectures and field investigations. HE Yan, president of our institute and deputy president of Beijing Society For Yuanmingyuan Studies, takes responsible for describing the amazing scenery and the five emperors' life in Yuanmingyuan during 150 years. Dr. Alexandra Harrer, an Austrian architecture researcher and a lecturer in the School of Architecture, Tsinghua University, mainly introduces the exchange and fusion of Chinese and Western architectural styles in Yuanmingyuan. THHS teachers in history and politics mainly lead students to review the event of looting and destruction of Yuanmingyuan and its influence on China's dealing with both domestic and foreign affairs, and to analyze and debate about the "repatriation rush" of looted Yuanmingyuan-associated cultural relics scattered overseas in recent years. THHS teachers in geology, by taking the Shizilin (狮子林) site in Yuanmingyuan as an example, explain the differences and relations between imperial gardens in Northern China and private gardens in Southern China. Our professionals lead students to survey and map the Hanjingtang (含经堂) site in Yuanmingyuan, interpret Yingzao suanli( 营造算例)—a classical tool book about traditional Chinese architecture from Qing Dynasty, and learn about the main styles and techniques of Chinese traditional architecture. Our specialists in digital restoration of the Western Buildings Scenic Area (西洋楼) in Yuanmingyuan and art teachers from THHS work together to instruct students to have a close look at the Western Buildings ruins, and admire the unique charm what the western buildings used to have.

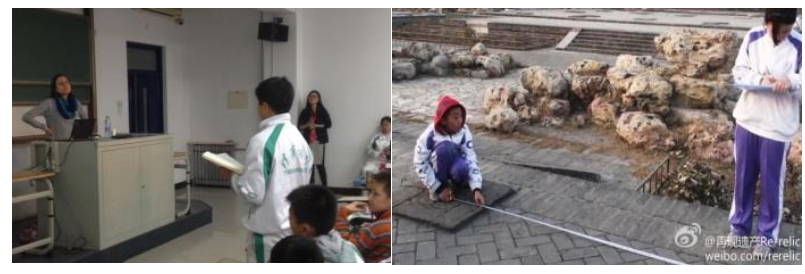

Figure 1. Students having class with Dr. Harrer and surveying Hanjingtang

In the second stage, emphases are placed on encouraging students to actively conduct inquiry learning. Students can choose the subject in which they are interested, make thorough study, and then try to display their study results in various ways. Teachers and instructors are not only responsible for providing students with method and practice instruction, but also accompany them by acting as an "assistant" or an "advisor". For example, the underground ruins of the theater in Hanjingtang are now a deep pit, and are protected by a thick grass shield. Students wanted to know its original form, so they applied ingenious methods and multi-disciplines in studying the ruins. To get the precise dimensions of the ruins, they designed various smart measurement schemes under the mathematics teacher's instruction, including the trigonometric function system to compute data. Through this process students not only knew more about cultural relics, but also further realized the measurement function of geometry. Some students were attracted by the underground furnace system in Hanjingtang, so they referred to relevant archives and material, investigated similar examples in the Forbidden City (紫禁城), analyzed factors like geology and hydrology, and finally wrote a paper to summarize their research results-"How did the Emperor Warm Himself in Winter". Some students turned into international tour guides; they sketched freehand tour guide maps, designed and composed guide text in English, and interpreted the beautiful scenery and evolution of the imperial garden. It was noticeable that some students lost themselves in traditional Chinese gardening culture, so they used the Sketchup software to design and present the imaginary ideal gardens in their minds, which were comfortable and easy for residence and tour. The amazing imagination and creativity of students made a deep impression on the teachers and our institute's professionals involved.

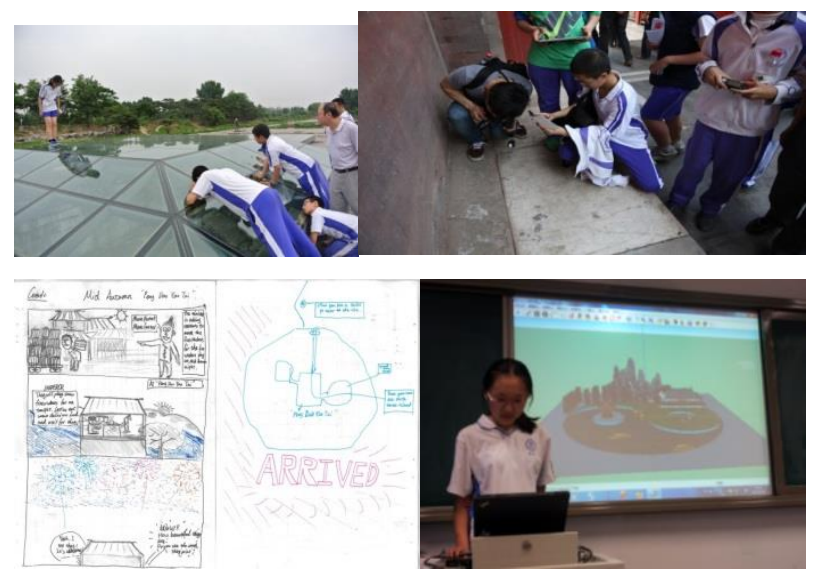


Figure 2. Students doing and presenting various research projects

Up to now has the "Into Yuanmingyuan" course progressed to the third generation, engaging more than 20 teachers and over 250 junior students altogether. It shows its charm and value in the admiration and acknowledgement of students; quite a number of junior students were intrigued and they sat in on the relevant classes designed by our institute for senior students in order to learn more about Yuanmingyuan and traditional Chinese architecture and gardens.

"Traditional Chinese Architecture and Gardens" for senior students is a school-based curriculum targeted first-grade students. At the beginning of each semester, professionals from our institute will publicize the curriculum to the whole grade, among other courses. The students will then listen for the first two weeks for trail, and select the course on their own decision. According to the cognitive features of senior students, this course takes class lectures as the main form, supported by documentary videos and field investigations, and increases the research depth and task difficulty at an appropriate level. Detailed agenda is shown as follows:

\begin{tabular}{|c|c|}
\hline Week & Conte \\
\hline 1 & $\begin{array}{l}\text { Introduction to traditional Chinese architecture : } \\
\text { gardens }\end{array}$ \\
\hline 2 & $\begin{array}{l}\text { Traditional Chinese architectural structures } 1-\mathrm{a} \\
\text { general view and the base }\end{array}$ \\
\hline 3 & $\begin{array}{l}\text { Traditional Chinese architectural structures 2-beams, } \\
\text { columns and dougong (斗栱) }\end{array}$ \\
\hline 4 & $\begin{array}{l}\text { Traditional Chinese architectural structures } 3 \text {-various } \\
\text { roofs }\end{array}$ \\
\hline 5 & $\begin{array}{l}\text { Watching a documentary: "Chinese Historical } \\
\text { Architecture: Exercising the Inventive Mind" }\end{array}$ \\
\hline 6 & $\begin{array}{l}\text { Field trip: Shizilin, Hanjingtang and Zhengjue } \\
\text { Temple(正觉寺) in Yuanmingyuan }\end{array}$ \\
\hline 7 & Introduction to traditional Chinese gardening art \\
\hline 8 & Chinese imperial gardens 1 -introduction of the history \\
\hline 9 & $\begin{array}{l}\text { Chinese imperial gardens } 2 \text {-Xiyuan (西苑) and the } \\
\text { Chengde Mountain Resort (承德避暑山庄) }\end{array}$ \\
\hline 10 & $\begin{array}{l}\text { Chinese imperial gardens 2-Three Mountains and Five } \\
\text { Gardens (三山五园) }\end{array}$ \\
\hline 11 & $\begin{array}{l}\text { Private gardens in the regions south of the Yangtze } \\
\text { River }\end{array}$ \\
\hline 12 & $\begin{array}{l}\text { Watching a documentary: "Chinese Historical } \\
\text { Architecture : Admiring Gardens with Lakes and } \\
\text { Mountains" }\end{array}$ \\
\hline & \\
\hline
\end{tabular}

Figure 3. Students having class "Traditional Chinese Architecture and Gardens"
This course has up to now been conducted for two semesters, and has received good feedbacks from students. In the first semester, there were 32 students selecting the course, while in the second semester, the number increased to over 60 . Among the students, one chose the theme "Understanding the History of Nan luoguxiang (南锣鼓巷) through Its Buildings” for writing an essay to participate in a composition contest about history. In his preparation, he contacted with our professionals for several times to collect material and seek suggestions. Over ten students chose themes related to traditional architecture and gardens as their study subjects in the "Inquiry Learning" course set up by THHS in its school curricula. These students invited our professionals to act as their instructors, under whose help, these students wrote a number of outstanding papers, including “Integrating the Charm of Sudi (苏堤) and the Fusion of the Mastery of Gardens - A Probe into the Inherent Gardening Culture in the Xidi (西堤) Scenic Area in the Summer Palace" and "A Research on Improving the Yuanmingyuan Temple Fairs".

Our success in these two courses drew the attention of the Education Department of Haidian District Government. They decided to promote the courses in all primary and high schools in Haidian District. The Education and Science Research Institute of Haidian District cooperated with the Yuanmingyuan Administration, organized relevant personnel to compose two textbooks titled Close to Yuanmingyuan respectively for primary and high schools. Our institute also engaged in the curriculum design, textbook compilation, providing and processing digital reconstruction images of Yuanmingyuan and other work. These textbooks have just been published in April, 2015.

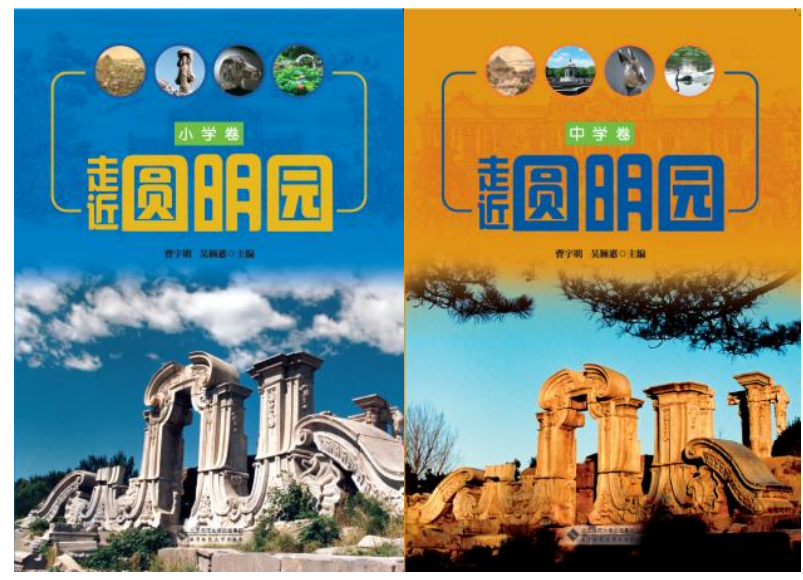

Figure 4. Covers of Close to Yuanmingyuan Textbooks

\subsection{Case 2: "History Is FUN"-independently cultural heritage summer camp}

Our cultural heritage education programs targeting teenagers are not limited within curriculum in schools. In June 2014,, based on the academic research of Tsinghua University, the digital technology in the Re-Yuanmingyuan program, and successful experience in the cooperation with THHS, we designed and held the "History Is FUN" themed summer camp, integrating multidiscipline contents such as history, culture, mathematics and architecture. This camp covered the whole area of Yuanmingyuan. It took the emperor's daily life in Yuanmingyuan and the implicit culture as the basis, carefully 
designed themed tour routes and special stages, with the support of Yuanmingyuan-specific mobile application software developed by our institute, led teenagers to enjoy themselves, to discover, to study and learn, to think and get inspiration. This activity turned out to be a success.

The 20 participants were Grade 1 junior students from Tsinghua High School, Beida Ziyuan High School and Beijing Sanfan Middle School, and they had a remarkable scientific and cultural experience tour in Yuanmingyuan.

\section{Stage 1: Getting to know Yuanmingyuan}

The summer camp was not only a "second classroom" for teaching teenagers, but also a good chance for them to cultivate their will, shape personality, and improve comprehensive capacity. In the first day, the 20 teenagers were randomly divided into four groups. In each group, teenagers worked together to decide the group name and slogan, to draw the group banner, and soon they got well acquainted with each other. In the competence development step, all groups, no matter the funny groups - the "Angry Bird" and the "Seven Calabash Brothers", or the elegant ones- "Exploring Yuanmingyuan in a Pure Posture" and the "Cyan Sail", all showed a spirit of solidarity and learnt communication and cooperation skills.

In addition, in order to expand teenagers' knowledge and prepare themselves for the activity, Ms. HE Yan and Dr. Alexandra Harrer gave two lectures to the teenagers, on Yuanmingyuan's evolution under the six emperors' construction and reform during 150 years, and the Chinoiserie -"Chinese style"- architecture and art popular in the West over the same period, respectively. The lectures were fresh and interesting to the teenagers, and they were quite absorbed. Dr. Harrer gave the lecture in English, and the teenagers understood quite well; they even took the initiative to pose and discuss questions.

However, It could not meet the teenagers' thirst for knowledge only through indoor lectures, so we demonstrated and employed the Re-Yuanmingyuan work results directly in exploring the relic sites. In Xieqiqu (谐奇趣) site, restoration professionals from our institute guided teenagers how to calculate dimensions like the height and width of the main building of Xieqiqu, by integrating the surveying, measuring and mapping of the relic site, the study of old paintings, photos and relevant materials all together, then to draw the supposed original design of the main building according to the teenagers' research and analysis. This way made it not so difficult for teenagers to learn about history and architecture, so they immediately became motivated. In their eyes, the ruins were no longer worthless stones, but a maze abundant with historical secrets waiting for them to figure out. The teenagers worked hard to explore, carefully measured, thoroughly thought and drew paintings with high concentration. Under their efforts, pieces of stone components became vivid, gradually formed into a whole structure, and the magnificent and fascinating scenery once existed in Yuanmingyuan came to life under the teenagers' brush.

\section{Stage 2: A Journey through History}

The second day was about "Exploring Yuanmingyuan", and it impressed the teenagers by the profound imperial garden culture rooted in Yuamingyuan. We designed four routes for the four teenager groups, and each route had a theme: 1) "No Easy Journey for Princes"- book collection and royal education; 2) "Appreciating Lotus on An Imperial Boat"-landscape of flowers and plants; 3) "Celebrating Harvest in the Field"observing crops and experiencing agriculture; 4) "Marvelous Craftsmanship Embodied in Flying Eaves and Curved Roofs"- architecture forms. Each route linked different theme-related scenic spots together, and formed into a comprehensive and rich-content sub-activity that the teenagers were going to experience. Each group chose a route, analyzed the clues available, answered the questions and completed the tasks assigned to them. When a group reached a spot, the cultural tutor from our institute would introduce its history and function, the meaning and historical funny facts associated with it. The teenagers got a deep understanding of the rich culture associated with Yuanmingyuan in their exciting conquer of the challenges and fulfilling tasks.

In addition to the research about history and culture, another distinctive feature of the summer camp was its application of high technology. The R\&D team of our institte specifically designed for the activity an ipad APP-FUN. Teenagers would get every clue through the APP; they could scan the 2D barcode hidden in the right place to get useful information to answer each question, so that they could get high scores and continue to challenge the next task. The APP could also be used to describe the history and culture related to each scenic spot, and display digital restoration images, which allowed the teenagers getting inspired and entertained the same time. Teenagers could also use the APP to determine their locations by using the map and GPS function, which could not only help to secure students, but also raise a group's score, for when a group arrived at a scenic spot and identified its name, they would be awarded with an additional "scenic spot achievement" score and get to see the restoration images and introduction about the spot. The teenagers did not confine themselves to the routes and assigned destinations; instead, they searched for each spot in Yuanmingyuan under the guidance of the APP, in order to know more. They were so energetic and thrilled about the new knowledge they gained about Yuanmingyuan that some even believed they could act as a tour guide for Yuanmingyuan after the camp.

The last step of Stage 2 was to assemble small wooden components into a model of dougong (斗栱), a critical and distinctive structure in traditional Chinese architecture. It was a challenge for the teenagers with no professional architecture background. First they categorized the wooden components as per form, size and drilling ways, tried to find the relations among different components, and gradually figured out the rule. After two days of cooperation, the members in each group could easily understand and well collaborated with each other, and finally four exquisite dougong models were generated under their efforts. Through this step, teenagers got a vivid and direct understanding and a deep impression about the elegant appearance and ingenious design of traditional Chinese wooden architecture.

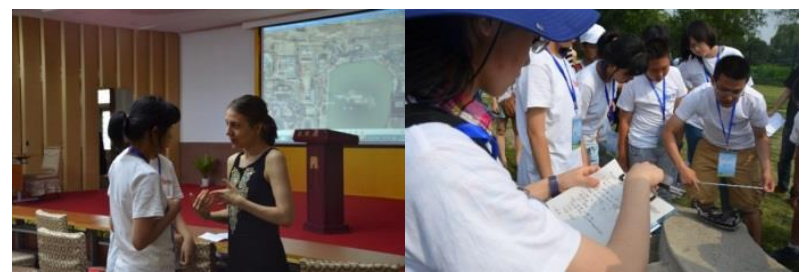




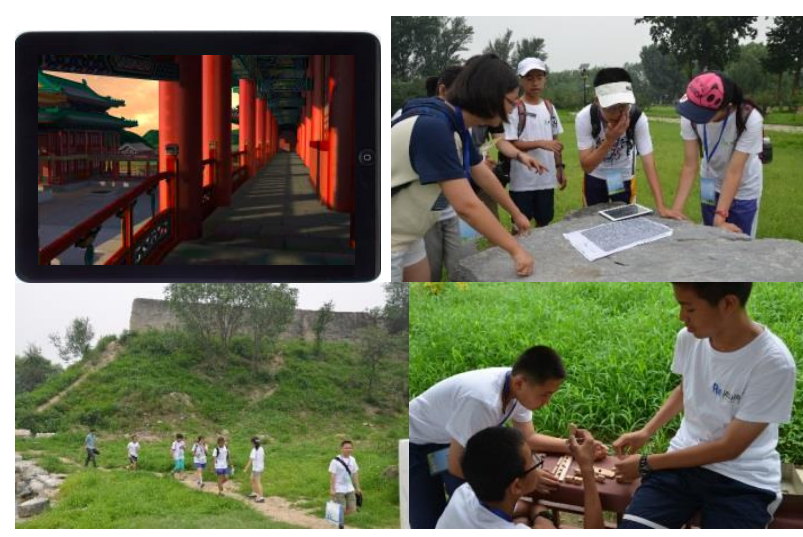

Figure 5. Moments of the "History Is FUN" Summer Camp

\section{Stage 3: Prospects in the Future}

In the evening of the second day, each group was asked to select six tools in turn according to the rank in the previous two stages, and use the tools to create a work that could show each group's perception of Yuanmingyuan. At that night the big conference hall became a workshop for teenagers to freely exercise their imagination and innovative minds, with smart ideas generated in brainstorming. The teenagers sat surround tables, referred to books and material, drafted texts and sketch pictures. They were so concentrated, just like scholars in a study room and generals preparing for an upcoming war. After deciding the scheme and assigning works, the teenagers immediately started to carry out their plans: writing and painting, cutting and clipping, pasting papers and snapping stuff, rehearsing and so forth. They were so devoted to striving for perfection and kept working constantly that teachers had to force them to have lunch or take a break.

Finally it was the presentation and appraisal of each group's work. Experts present at the presentation include Professor GUO Daiheng, a famous architecture historian from Tsinghua University and the honorary president of our institute, Ms. HE Yan and Dr. Alexandra Harrer. In addition to the experts and professionals from our institute, there were numerous parents and teachers who came to support the teenagers. At the beginning, a short video was played, reviewing all moving and exciting moments in the summer camp, evoking the teenagers' good memories and arousing other people's interest. Next to the video was the performance of the teenagers. They either played witty skits, dramas and cross talks, or danced, or recited poems, fully displaying their talent in eloquence, imitating, amusement and singing. They acted as either emperors, queens, concubines, princes, guards, courtiers, envoys, intellectuals or even time travelers; they narrated the stories about and their feelings towards Yuanmingyuan in a tone that was immature but full of wisdom. Well-designed PPT slides and music, lifelike and delicate paper costumes, fancy but vivid landscape drawings on T-shirts, all of these showed the teenagers' amazing imagination and creativity, and impressed all people present. The teenagers just spent half a day in preparing for the final presentation, but gained rich and noticeable results. They thought about the rise and fall of dynasties, appreciated the prevailing imperial garden styles in history, and cooperated closely with each other to fulfil tasks set up for each group. The friendship, mutual trust, teamwork and strategies they showed during the whole activity, as well as the teenagers' thorough thinking about history and brilliant ideas, went far beyond the organizer's expectation. In the over-two-hour presentation, people enjoyed a feast for the eyes, with joys, applauses and exclamations of admiration throughout the performance. A parent said excitedly:" This has been really amazing! The summer camp has offered not only a lot of fun, fine catering and accommodation, which is assuring to us parents, but also great opportunity to learn, to think, to feel and to comprehend. It's meaningful and valuable."

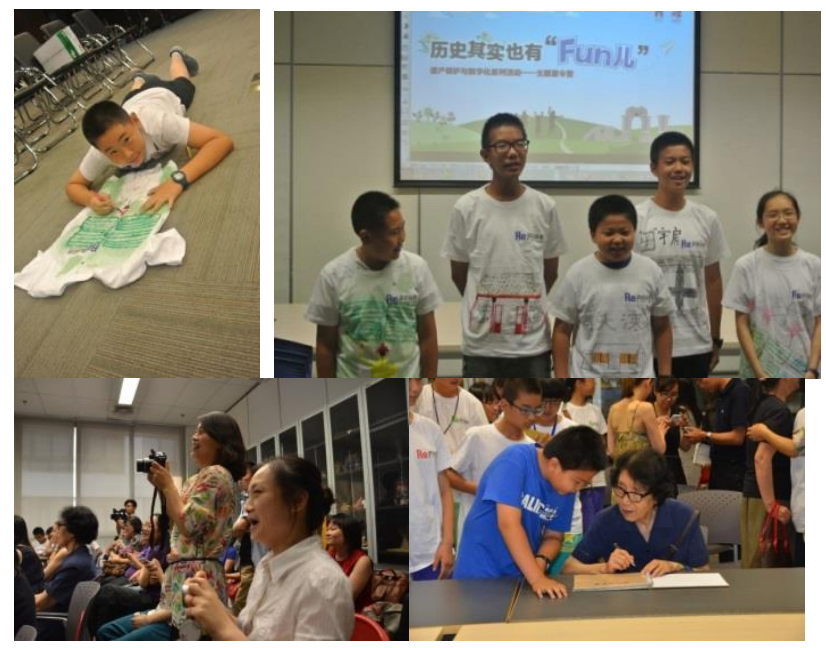

Figure 6. The Presentation Section of the "History Is FUN" Summer Camp

\subsection{Case 3: Pass the Flame-teenagers' participation in international cultural heritage symposium}

In September 2014, the $3^{\text {rd }}$ International Symposium on Cultural Heritage Conservation and Digitization (CHCD) was held in Beijing, co-hosted by the International Scientific Committee for Documentation of Cultural Heritage (CIPA), Chinese Commission for The International Council on Monuments and Sites (ICOMOS China), and the School of Architecture, Tsinghua University. Our institute co-organized the symposium with two other institutions. On the symposium, We designed a special section-"Pass the Flame: Teenagers and Cultural Heritage", chaired by Professor WANG Guixiang from Tsinghua University. At the beginning of this section, a video about Mr. ZHOU Ganzhi, academician of both the Chinese Academy of Sciences and the Chinese Academy of Engineering who was played. He delivered an enthusiastic speech on the $2^{\text {nd }}$ CHCD Symposium (2012), expressing his opinions about the status quo of Chinese cultural heritage conservation but unfortunately passed away in March 2014. After the video, student representatives from the "Into Yuanmingyuan" course and the champion group from the "History is FUN" themed summer camp made presented their rich results and benefits gaining from these activities, both in knowledge and thought. This section aimed to convey such a wish that though $\mathrm{Mr}$. ZHOU Ganzhi was no longer with us, the young generation would take up the responsibility for conserving and promoting cultural heritage. The excellent performance with the teenagers' sincerity and genuine enthusiasm impressed the guests present and earned warm applauses

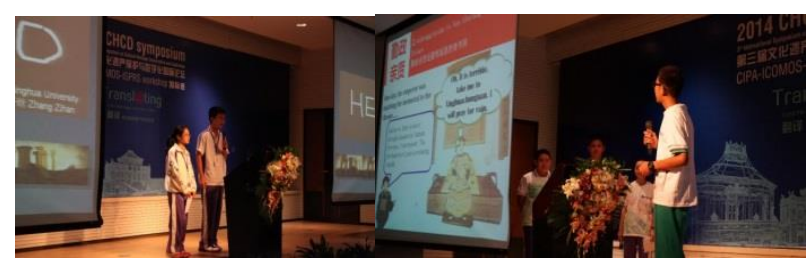


Figure 7. Students giving presentation on CHCD symposium

In addition to the special section on the international symposium, we also figured out a way to engage teenagers in the professional international workshop on the Western Buildings Area in Yuanmingyuan held at the same time with the symposium. Teenagers were appointed as "Teenager Observers", assigned to five groups to observe how each group conduct their research object, and to provide possible assistance. The workshop members were from different countries, under the instruction of international scholars and experts in specific and relevant research fields. Teenagers closely observed what the instructors and group members did, asked questions, discussed matters and exchanged opinions with the instructors and group members. In this process, they got to know about the real research processes, and got access to first-hand information about relevant subject. In the last section, when each group reported their research results in this workshop, these "Teenager Observers" were also invited to report their work assigned to them. A teenager said "What impressed me most was that everybody could fulfill his duty and show his value in my group, no matter you are a specialist, a member or just a child like me. People were friendly and respectful to each other in my group. Though everybody trusted and respected the instructors, we would not blindly believe every word he said; neither did we take his suggestions as absolute truths without analysis." Another teenager made a remark about his experience in the workshop, "I have learnt a lot of useful information. For example, in carrying out our research, some guy in my group offered a book which introduced traditional Chinese decorative patterns in detail. This book helped us compare Chinese decorative patterns with those of the West. Reading this book made me feel as if I could be a specialist in this matter."

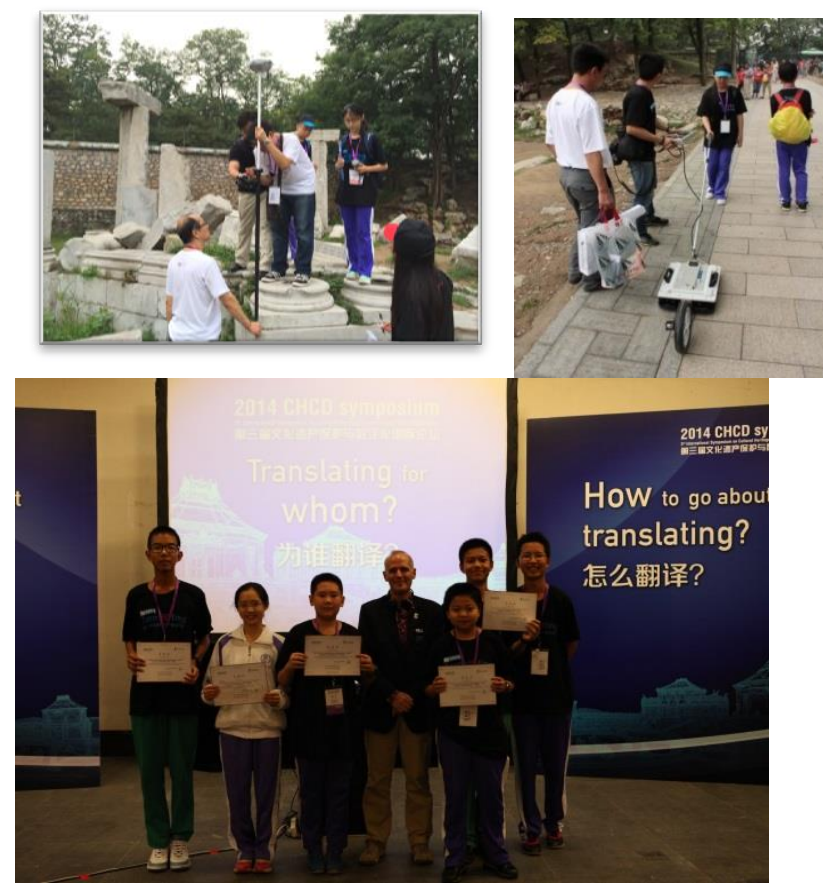

Figure 8. Students participating CHCD workshop

This fresh and unordinary try by involving teenagers into research as an observer had won recognition and praise from not only teenagers, members and instructors in the workshop, but also researchers and practitioners in relevant fields and the press present at the report meeting.

\section{CONCLUSION}

The practice of cultural heritage education in Yuanmingyuan site has proven welcome among teenagers, appreciated by parents and teachers, and meaningful and valuable for the conservation of the heritage site. Currently, We are striving continually to improve the program design, with the purpose of achieving a more diverse and lively form, richer content, more satisfactory teaching/learning effect and more fruitful results.

\section{REFERENCES}

ICOMOS Guidelines for Education and Training in the Conservation of Monuments, Ensembles and Sites (Colombo, 1993);

ICOMOS Charter for the Interpretation and Presentation of Cultural Heritage Sites (Quebec, 2008);

\section{UNESCO, 1998, World Heritage in Young Hands;}

National Outline for Medium and Long-term Education Reform and Development (2010-2020) of China;

GUO Daiheng(郭黛姮), 2007，《乾隆御品圆明园》 